\title{
The Impact of Globalisation and Industry 4.0 on Training and Re-Training in Developing and Undeveloped Nations
}

\author{
Nissi Kalio \\ Faculty Management Science, Rivers State University, P.M.B 5080, Nigeria
}

\begin{abstract}
Globalization has come to stay and it is imperative for countries to sail with the flow of recent trends. As a developing or an underdeveloped nation we stand at the edge of a technological explosion, birthing the $4^{\text {th }}$ industrial revolution and advancement (industry 4.0) which is a transformational experience desired to affect the way we live and work especially at the organisational level for both private and public business. The sad truth is, this future we desire and consider complex, is already in place as a working system for developed nations. We do not have an inclination as to how it will work, it important developing and underdeveloped nation of the world response to the needful and fully integrate comprehensively into globalisation and industry 4.0 by training and re-training (learning, unlearning and relearning).
\end{abstract}

Keywords: Globalization, Industry 4.0, Training, Retraining, Developing and Underdeveloped Countries. DOI: $10.7176 / \mathrm{EJBM} / 11-3-19$

\section{Introduction}

Globalisation is fast growing, necessitating the dependence of nation. The resultant effect includes; free movement of labour, good and services, technology etc Globalisation allows for worldwide economic activities because there is a borderless world we now refer to as a global village. Globalisation has become a natural occurrence eating deep into the nook and crannies of countries, aiding with industrialization thereby making the developed countries better. It is said that the process of development with respect to countries is relative but the impact of training and re-training can help even underdeveloped and developing nations come up with speed. The new world is change driven and welcomes radical development for businesses: the interaction between countries fosters industrialization. Globalization is the thread that ties nations together, with innovation around technology imperatively affecting trading activity. This paper is centred around the impact globalisation and industry 4.0 has on employees and the role of training and re-training of such employees skills in order to matchup with the demand of todays world.

\section{Globalisation}

Globalisation has helplessly taken the world into captivity though positive and inevitable. It depict growth and progress when the entire world is interconnected. The history of globalization goes back to the second half of the twentieth century $\left(20^{\text {th }}\right)$, the development of transport and communication technology led to situation where national borders appeared to be too limiting for economic activity. Globalization is a rising international network, belonging to an economic and social system (Fox, 2001). Globalization refers to a rapid interconnectivity that is broad that is to say it can be viewed at the local, the national and the regional point, connection is made between social and economic relationships and networks. Globalization is a concept that explains the idea for the practice and theory of the business transaction and operations, it also describes the spread of communication production and connection technologies throughout the world. Globalisation brings the world closer involving the spread of ideas, processes. Practice and the use of technology. The issue around globalisation is that the gap that exist between rich and poor countries is never bridged. The impact of globalization tends to affect the economic growth, employment and income distribution of countries equally and other impacts such as opportunities for poverty alleviation, environmental consequences etc. It is the process an organisation develops influence internationally: with the aim of increasing interaction between people, organisation and countries. Globalization is primarily an economic process of integration that has social and cultural aspect involving the transfer of goods and services, and the economic resources of capital, technology, and data communication technology etc. The concept of globalization refers to the measures of developmental significance in all regions of the world irrespective of the diversity, cultures, belief systems etc (Castells 2001). Globalization is social, political and economic stretch giving room for interconnection and interaction in the flows of trade, investment, finance, migration, culture etc. Globalisation or contemporary globalization is the face of technology and it shrinking the world today via information communication and technology; driven by economic, technological, political and cultural shifts.

\subsection{Advantages of Globalization}

i. Wide spread of technology

ii. Increased liquidity of capital that allows for investment 
iii. Increased trade between nations

iv. Greater flexibility of operation

\subsection{Disadvantages of Globalisation}

i. Exploitation of developing and underdeveloped nations

ii. Increased wealth inequality

\subsection{Dimensions of Globalisation}

There are five dimension to be considered for this work
a) Economic
b) Political
c) Democracy
d) Ecological
e) Culture

From the economic dimension, global finance and market of economy, multinationals, networking, international trade and business, new labour markets, new development cooperation are viewed.

Political dimension concerns are human rights, international terrorism, war and new security problems.

Democracy dimension focus is on good governance by people's participation, human rights.

Ecological dimension is interested in sustainability of biosphere e.g. water, forest, earth, air, and atmosphere

Cultural dimension is multifarious and multicultural at the local, political, gender, family, religious, national, individual and social aspects.

There is wide digital divide, we can generalise the saying, the world is unequal seeing that in developing and underdeveloped nations lack access to the most basic and major driving force of globalization today called technology.

\subsection{Globalization and Developing Nations}

Globalization is playing an increasingly important role in the developing countries. It can be seen that, globalization affects the economic processes, political activity, health systems, education too etc. Globalization has propelled a new opportunity for developing countries in the area of technology that affects how we do things as a nation affecting even the learning process of imbibing new knowledge with greater opportunity to access developed nation's market, growth and improved productivity and living standards. The truth is not all effects are positive in the sense that globalization has also brought up new challenges such as, environmental deteriorations, instability in commercial and financial markets, increase inequity across and within nations (Kotilainen \& Kaitila 2002). Recently there has been a surge of financial globalisation with respect to capital flow among industrial countries in the line of academics and policies. The flow is associated with high growth rates for developing nation. Globalization has contributed immensely to the development of the educational systems in the developing countries. We can clearly see that education has increased in recent years, because globalization has a catalyst to the jobs that require higher skills set.

\subsection{Globalization and Underdeveloped Nations}

Underdeveloped nation poses a threat to globalisation especially when there is no drive to be at par with other nations of the world. Sadly as a country we seem to fall within this category of people. Globalization is nation specific in the sense that it depends on where nation started off and how globalization is viewed from the perspectives of undeveloped nation, in developing nations, focus is on workers with respect to the factories they work in, their exposure to skills, down to the wages they earn. According to Flemming (2001), Globalization has not really solve the issues of poverty in underdeveloped nations rather it has projected the vulnerability of this region thought somehow they still thrive to interact with other part of the world at a slow pace.

\section{Industrial Revolution (Industry 4.0)}

Industry 4.0 is a German initiative and the revolution depicts a change that is complete, total and whole, it is a fundamental change at it were in political power resulting from the peoples revolting and engineering against the activities of the incumbent. Industrial revolution is connected to the revolution within the place of business for transformational goods and services. It a major change of technology, socioeconomic and cultural. The first industrial revolution happened in the $18^{\text {th }}$ and early $19^{\text {th }}$ century resulting from the replacement of an economy based on manual labour to an economy dominated by machines. But for the course this work focus is the fourth industrial revolution (industry 4.0). The First Industrial Revolution used water and steam power to mechanize production. The Second used electric power to create mass production. The Third used electronics and information technology to automate production. Now a Fourth Industrial Revolution is building on the Third, in fact it is a disruption of the third, it a re-invention of the third, it is the digital revolution that has been occurring 
since the middle of the last century that is being characterised by a blend of technologies that is still in the abstract but exiting in some countries. The fourth industrial revolution is a merger of four worlds: physical, digital, and biological. It is today's transformation and it a distinct one with changes in the entire systems of production, management, and governance (Schwab, 2016). We see the prospects in the large number of people that are being connected via mobile technologies. It is obvious that with an unprecedented power storage capacity and unlimited access to knowledge, there will be a view of possibilities that is propagated by new technology in areas such as artificial intelligence, robotics, autonomous vehicles, 3-D printing, nanotechnology, biotechnology etc.

According to Schwab (2016), Ubiquitous, mobile supercomputing, intelligent robots, Self-driving cars, Neuro-technological brain enhancements, Genetic editing, are all evidences of a dramatic change happening at exponential speed globally. He believes that we are at the beginning of a revolution that is fundamentally changing the way we live, work and relate to one another totally impacting all disciplines ranging from economies and industries. The disruptions of the fourth industrial revolution poses a time of great promise and great peril bringing the world together connecting billions of people to digital networks with an estimated number of 25 billion people by 2020 with a financial estimated impact of $\$ 1.7$ trillion by 2020 and $\$ 6.2$ trillion 2025., dramatically improve the efficiency of organizations and even manage assets in ways that can help regenerate the natural environment, potentially undoing the damage of previous industrial revolution (Jurgen, 2012). Technological advancement allows for countries to learn, carry business activities, free access, etc with other countries aiding the idea of globalisation.

\subsection{Benefits of Industry 4.0}

1) Transparent information

2) Technical Support

3) Productive and decentralized decisions

4) Cloud technological storage of big data

\subsection{Challenges of Industry 4.0}

Industry 4.0 is a desired end with ample opportunities for all and sundry but it still leaves us in grave dangers of

1) Countries especial developing and underdeveloped to be able to might be adapt because the governments foreseen failure to employ and regulate new technologies.

2) IT security issues, which are greatly aggravated by the inherent need to open up those previously closed production shops

3) Lack of adequate skill-sets to expedite the move of the fourth industrial revolution

4) Loss of jobs to automatic processes and IT-controlled processes

\section{Globalization and Industry 4.0}

The Fourth Industrial Revolution is global affecting the entirety of the universe, improving the quality of life of the people around the world. Technology has open a new world of possibilities both for the developed and more for the underdeveloped and developing nations of the world. Affordability and access has been the issue with the $3^{\text {rd }}$ world countries. Available technologies is in bits and pieces of the different categories of industrial revolution. The economic concern of inequality represents the greatest societal and global challenge associated with the Fourth Industrial Revolution. Nations with innovation and creativity on technological advancement will still be the providers of intellectual and physical capital, the innovators, shareholders, and investors leaving the rising gap of wealth between those nations that are capital driven to those that are labour-driven. Technology is therefore one of the main reasons why incomes have stagnated, or even decreased, for a majority of the population in high-income countries: the demand for highly skilled workers has increased while the demand for workers with less education and lower skills has decreased. Globalisation has exposed the population of countries into a technology enhanced economy where over half of the population (especially the young) uses social media platforms to connect, learn, and share information. In an ideal world, these interactions would provide an opportunity for cross-cultural understanding and cohesion (Markus \& Andreas, 2013). The emergence of global platforms has transformed thoughts pattern and learning to understand the direction of these new technologies. However, we must develop a comprehensive and globally shared view of how technology is affecting our lives and reshaping our economic, social, cultural, and human environments.

\section{Training and Re-Training}

The labour act states that, it is the employer's obligation and duty to develop the human resource available to the organisation by way of training and retraining the workers in order to bridge the identified gaps/lapses that will help sharpen their skills and competences (Omole, 1999). Industry 4.0 impacts the current globalization and innovation trend. Organisations will play a major role in training their employees in the line of this new 
technologies. The impact of technology on training is transformingly amazing. An organisation of the future is one in which employees will no longer be able to rely on training from a skill or a line of discipline but development as an integral part of the job will necessitate on the job training and retraining from time to time to keep up with the demands technology driven globalization has placed on them: transformation at the workplace is technology based. According to Imhabekhai (2000), he says the traditional based method of training, contact is needed to teach e.g. teacher to student but with technology virtuality is key (web-based learning); training is achieved via video links, virtual plays and simulations. Organisations must embrace these techniques especially the use of virtualisation. Learning is taking a different dimension, it will become more systemic in its processes and methods: adaptively and geographically mobile. Training will show this trend e.g. imagine an alert system that helps you understand and complete tasks more effectively and efficiently.

\subsection{Impact of Globalisation and Industry 4.0 on Training and Re-Training of Employees in Developing} and Nations.

The advancement of globalization and increasing level of technology has necessitate the drive for the acquisition of knowledge and skills in employees of developing and underdeveloped nations through training, retraining and learning, this singular act is drastically reducing the demand for unskilled labour and uneducated employee, thereby raising the bar of value and competences of individuals. The workplace requires highly skilled workers for a broader and technologically enhanced organisation. Globalisation has birthed new technological changes such as industry 4.0 creating a vacuum of knowledge for the employees especially those within the challenging environment labelled developing and underdeveloped (Markus et al, 2013). Labour force in developed nations has grown so rapidly greatly affecting the economic growth and productivity. Training and retraining can positively enhance income, standard of living form the micro level of the economies to the macro level. Industry 4.0 is a higher and new frontier of technology posing a skill desiring acquisition especially by organisation willing to stand the new face of technology.

Industry 4.0 (fourth industrial revolution) is not an initiative to secure the survival of developing countries. It is rather a shift towards the new and contemporary production method leading to further globalization for the small and medium organisation crowding the developing and underdeveloped nations. Organisation operates in an enabling environment to create a balanced ecosystem that can boost productions on their global capabilities and potentials in nations below the standard. This a period of major change, McKinsey defines it as the next phase in digitization, driven by a sharp rise in data volumes, computational power and connectivity, the emergence of analytics and business intelligence capabilities, new forms of human machine interaction and improvements in transferring digital instructions to the physical world, such as advanced robotics and 3D printing (Markus \& Andreas, 2013). There is a positive direction that will lead to increase in productivity, innovation, and profitability. Industry 4.0 is huge and changes will very drastic, no organisation wants to be met unprepared. It imperative for the organisation especially in the line tagged developing and underdeveloped nations to be adequately prepare by developing the skills of her labour via training and retraining. The diagram below shows the impact of training and re-training on the $21^{\text {st }}$ century employee:

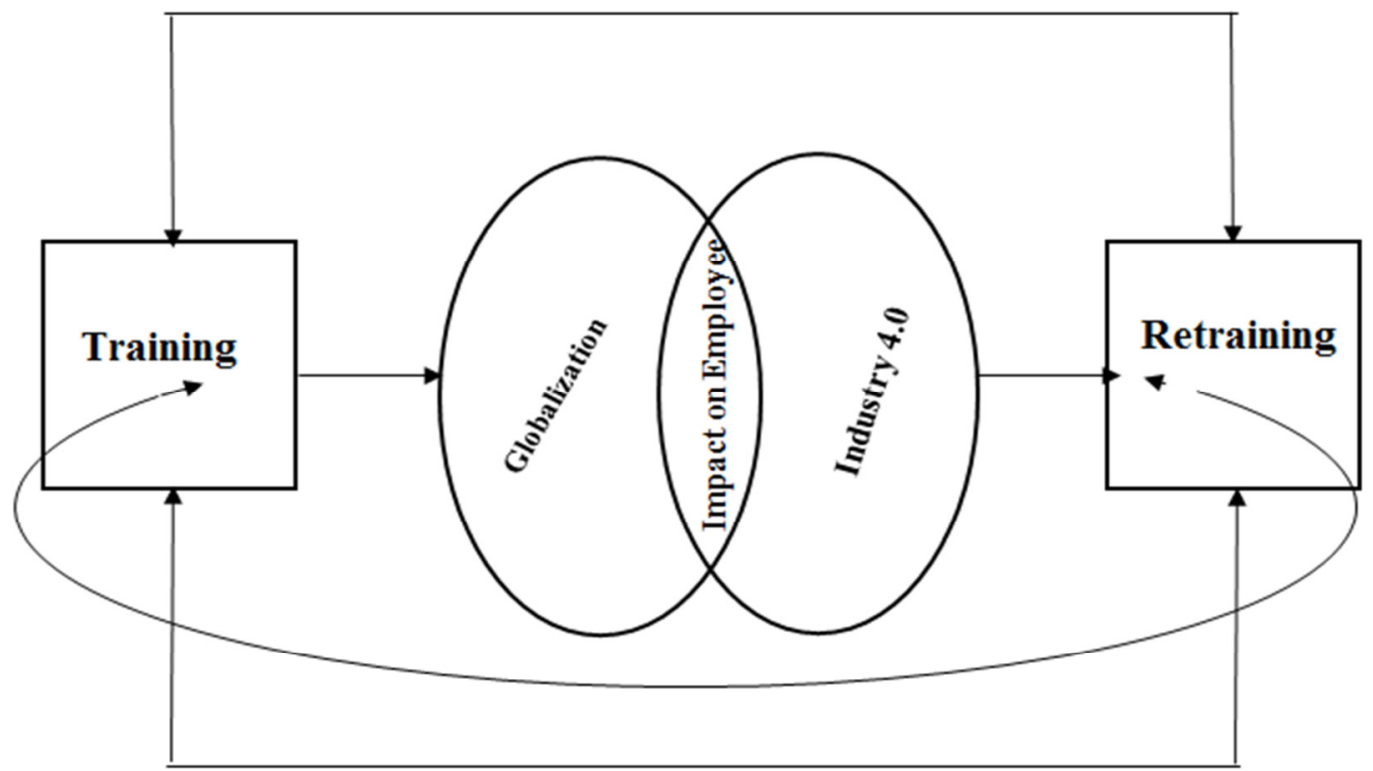

Figure 1. The Connectivity Chat of Training and Re-Training of Globalisation and Industry 4.0 on employees. Source: Researches Desk 
From the illustration above Globalization and industry 4.0 can be fully be grasp by employee through adequate training and re-training where necessary. Concerns are centred more on how organisation within this environment of development can adapt to this awaiting paradigm shift and the still remain relevant in the future where most advanced technology are at the verge of the next industrial revolution. According to Hermann (2016), this is a period of transformation, the old methods will disappear birthing the new, and he further stated that globalization is a precondition for Industry 4.0, which is dependent on seamlessly sharing data to enable smart production and flexible manufacturing decisions. Some years ago, precisely 1966, the United Nations General Assembly adopted a resolution establishing the United Nations Industrial Development Organisation on a continuous to work to eradicate global poverty by assisting developing and low-income countries in achieving inclusive and sustainable industrial development.

Looking at industry 4.0 and globalisation, it is hard to say that organisation in the developing and underdeveloped nations are ready to adapt to the big-change of the future, knowing fully well that they bag a heavy load of challenges with respect to technological advancement.

Factors to consider for training in developing and underdeveloped regions

1. Awareness and readiness

2. Data explosion

3. Transformation of workforce and workplace

Marr (2014) emphasised the need to upgrade skills at the workplace and we must learn to understand and collaborate with the intelligence of machines at our disposal. There hope for developing and underdeveloped nations because industry is the recent and if we put our minds to it, we can achieve it and be at par with the developed nations of the world.

According to Sundararajan industry 4.0 is a level playing field for those countries that missed the early waves of automation and industrialization, he further outlined the three major challenges to developing countries as

- Skillsets: In developing countries reskilling does not take place. There are specific skillsets that are needful e.g. robotic programming and Big Data Analytics.

- Scalability: several enterprises are at the beginning level of Industry 4.0 (design and implementation). But they are yet to scale up beyond organisations.

- Funding: sponsorship is key, organisation need the fund to attain industry 4.0.

- Industry 4.0 technologies: this technology will be possible only when the respective technologies, interfaces, and formats have been put in place.

- $\quad$ Value chain upgrading through the use of digital technologies, processes and products

- Structural transformation: the social and organisational factors influenced by demographic changes in different groups of developing countries.

- $\quad$ Set up knowledge sharing platforms: where learning can take place by doing

Skills are needed to bridge the gap that exist between engineering and computer science, machine learning and artificial intelligence. How we work will change and involve a shift towards knowledge based jobs and task. There will be robotic and automation designers, intelligent system engineers, and ecosystems of automation technologies. There will be a new software business in automation etc (Jurgen, 2012). Training and retraining become key to developing manpower skills thereby projecting a better nation and human resources skills is enough to move developing and underdeveloped nation into developed nations e.g. china.

\section{Conclusion}

A globalised Industry 4.0 contributes to creating a new wealth that can further exceed standards of living. The industrial revolutions of time past is improves an economy, having a better way of living and achieving results. This revolution is big, it is disruptive, it is innovative, and it is a desired change to enhance nations. We must be well equipped by way of upgrading skillset via learning through training and retraining, readiness of employee should meet availability of technology that is affordable for developing and underdeveloped nations to use. This change has a move for collaboration replacing competition. We cannot tell the future, we can see glimpse of it, organisations should think ahead, embracing the change the future offers, accept new ideas and prepare the workforce for the challenges of the future. Industry 4.0 is a flexible technology that enables learning, e-learning through social media and their likes with contents delivered by employer. The impact of training and retraining using platforms like the social media is ideal creating an avenue for growth and development. The truth is social media is most used tool and it has changed the way we interact with each other thereby aiding learning and equipping the future. Digitalised reporting and big data management is giving the workplace a new view and scope, information is accessed and exchanged easily and eases out the work tension associated with meeting deadlines 


\section{References}

Beck, U. (1992). Risk Society, London, Sage.

BMBF-Internetredaktion (2016). "Zukunftsprojekt Industrie 4.0 - BMBF". Bmbf.de. Retrieved 2016-11-30.

Castells, M. (2001). Information technology and global capitalism. Hutton and Giddens (eds.) On The Edge. Living with global capitalism, London: Vintage.

"Challenges and Requirements for the Application of Industry 4.0: A Special Insight with the Usage of CyberPhysical System". cjme.springeropen.com. Retrieved 2018-01-01.

Flemming, L. (2001). Globalization and the poor countires: viewpoint of IMF. Europe

Frank, T. (2002). One Market Under God. Extreme capitalism, market populism, and the end of economic democracy, London: Vintage.

Fox, J. (2001). Chomsky and Globalization, London: Icon Books.

H2020 CREMA (2016). Cloud-based Rapid Elastic Manufacturing". Crema-project.eu. 21 November 2016. Retrieved 2016-11-30.

Held, D., McGrew, A., Goldblatt, D. and Perraton, J. (1999) Global Transformations - politics, economics and culture, Cambridge: Polity Press.

Heiner, L., Hans-George, K., Peter, F., Thomas, F. and Michael, H. (2013). Industry 4.0. Business \& Information Systems Engineering 4 (6), 239-242.

Hermann, P. O. (2016). Design Principles for Industrie 4.0 Scenarios, accessed on 4 May 20.

Hutton, W. and Giddens, A. (2001). On The Edge. Living with global capitalism, London, Vintage.

Imhabekhai, C.I. (2000). Manpower Training and retraining for effective health care delivery Benin Journal of Education Studies, (12\&13) 1\&2.

Jurgen J. (2012). Was hinter Begriffen wie Industrie 4.0 steckt in Computer \& Automation, 19 December 2012 accessed on 23 December 2012.

Jurgen, J. and Oliver, N. (2012). Intelligente Assistenzsysteme zur Beherrschung der Systemkomplexität in der Automation. ATP edition - Automatisierungstechnische Praxis, 9/2012, Oldenbourg Verlag, München, September 2012

Kagermann, H., Wahlster, W. and Helbig, J. (2013). Recommendations for implementing the strategic initiative Industrie 4.0: Final report of the Industrie 4.0 Working Group.

Kotilainen, M \& Kaitila, V. (3/2002)."Economic Globalization in Developing Countries", The journal of Economic in Developing Countries, (70).

Marr, B. (2014). "Why Everyone Must Get Ready For The 4th Industrial Revolution". Forbes. Retrieved 201802-14.

Markus, L. and Andreas, T. (2013). "The Internet of Things and the future of manufacturing | McKinsey \& Company". Mckinsey.com. Retrieved 2016-11-30.

Omole, M.A.L (1999). Industrial Education and Human Resources Development. Ibadan, Alafas Nigeria company

Scholte, J. A. (2000) Globalization. A critical introduction. London, Palgrave.

Schwab, K. (2017). The Fourth Industrial Revolution. New York, Crown Publishing Group. ISBN 9781524758875

Schwab, K. (2016). The Fourth Industrial Revolution. World Economic Forum. ISBN 1944835008.

Schwab, K. (2017). "The Fourth Industrial Revolution: what it means, how to respond". World Economic Forum. Retrieved 2017-06-29.

"The Fourth Industrial Revolution: what it means and how to respond". World Economic Forum. Retrieved 2018-03-20.

Thirlwall. A. P. (2003), "Growth \& Development with special reference to developing economies", (7th ed). Palgrave Macmillan: New York. 